\title{
Effects of Power-Law Plasticity on Deformation Fields underneath Vickers Indenter"
}

\author{
Nuwong CHOLLACOOP**, Gollapudi SRIKANT*** \\ and Upadrasta RAMAMURTY *** \\ ** National Metal and Materials Technology Center (MTEC) \\ 114 Thailand Science Park, Pathumthani 12120, THAILAND \\ E-mail: nuwongc@mtec.or.th \\ *** Department of Metallurgy, Indian Institute of Science, \\ Bangalore 560012 INDIA
}

\begin{abstract}
The effects of power-law plasticity (yield strength $\sigma_{\mathrm{y}}$ and strain hardening exponent $n$ ) on the plastic strain distribution underneath a Vickers indenter was explicitly investigated by recourse to macro- and micro-indentation experiments on heat-treated Al-Zn-Mg alloy. With carefully designed aging profile, Al alloy can achieve similar $\sigma_{\mathrm{y}}$ with different $n$, and vice versa. Using the Vickers tip, the samples were macro-indented, sectioned and micro-indented to construct the sub-surface strain distribution. Thus, the effects of $\sigma_{\mathrm{y}}$ and $n$ on stain distribution underneath Vickers indenter were revealed.
\end{abstract}

Key words: Power-Law, Vickers Indentation, Deformation Field

\section{Introduction}

Instrumented sharp indentation, where load $P$ and depth of penetration $h$ being measured continuously, has been used widely as a non-destructive tool to probe and extract mechanical properties of the indented sample, due to its ease of sample preparation, requirement of small volume and simple test procedure. It is not surprising to see instrumented indentation being used to measure properties of materials at nano-, micro- and macro-scale or in various disciplines ranging from biology, food science and pharmaceutical industry. Nonetheless, complex elastic-plastic contact mechanics during the indentation has called for direct experimental observation to support limited theoretical framework. In the present study, cross-section deformation behavior underneath Vickers indenter was experimentally investigated, following the method of Chaudhri ${ }^{(1)}$. The plastic strain distribution was then correlated to yield strength $\left(\sigma_{\mathrm{y}}\right)$ and strain hardening exponent $(n)$.

\section{Experimental Procedure}

A commercial $7075 \mathrm{Al}$ alloy (Al-7.6Zn-4.6Mg-1.0Si, wt $\%$ ) was machined for tensile specimens with $35 \mathrm{~mm}$ gage length and $3 \times 1.6 \mathrm{~mm}^{2}$ cross section, with a thickness of $2 \mathrm{~cm}$. All specimens were solutionized at a temperature of $480^{\circ} \mathrm{C}$ for 2 hours and aged at a temperature of $150^{\circ} \mathrm{C}$ in an oil bath, in order to achieve the most symmetrical hardness $H$ vs. aging time $t_{\mathrm{a}}$ curve $\mathrm{e}^{(2)}$. At each $t_{\mathrm{a}}$, the hardness value of each sample was determined by measuring the average of the two imprinted diagonal lengths (of the roughly square shape) after the indentation load of $30 \mathrm{~N}$ at the grip section. The hardness value in $\mathrm{kgf} / \mathrm{mm}^{2}$ was then converted to MPa by multiplying a conversion factor of 9.807 , see Table 1 . Then, each sample was subjected to a uniaxial tensile testing at a strain rate of $10^{-3} 1 / \mathrm{s}$ to obtain $\sigma_{\mathrm{y}}$ 
and $n$. Figure 1 shows the plots of $H, \sigma_{\mathrm{y}}$ and $n$ vs. $t_{\mathrm{a}}$ so the aging profiles were selected at $t_{\mathrm{a}}=6,36$ and $94 \mathrm{hrs}$ so that $\left(\sigma_{\mathrm{y}}, n\right)$ can be of value (348 MPa, 0.07), (445 MPa, 0.066) and (344 MPa, 0.11), respectively (see Table 1). To analyze the effect of yield strength, the aging times of 6 and $36 \mathrm{hrs}$ can be compared. On the other hand, the effect of strain hardening exponent can be analyzed by comparing the aging time of 6 and $94 \mathrm{hrs}$. Figure 2 shows the true stress-true strain curves of the three aging profiles prescribed, quantifying detailed mechanical properties of these three conditions. For each $t_{\mathrm{a}}$ value, cylindrical samples of $15 \mathrm{~mm}$ in height and $10 \mathrm{~mm}$ in diameter were given various levels of compressive plastic strain $\varepsilon_{\mathrm{p}}$ at a strain rate of $10^{-3} 1 / \mathrm{s}$, prior to micro-hardness measurement. Then, the conversion graph from micro-hardness to plastic strain for each aging time was created.

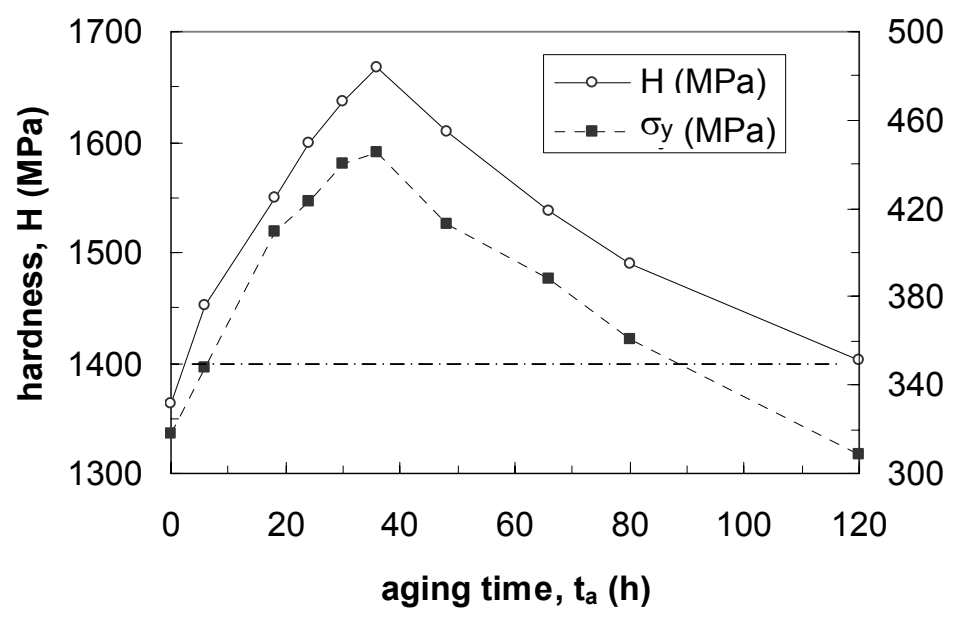

(a)

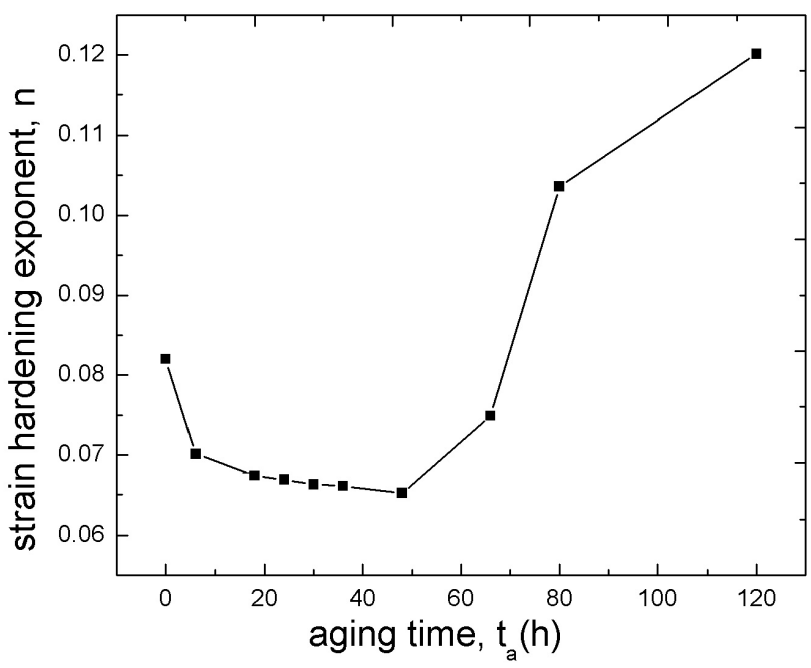

(b)

Figure1. Aging profiles for (a) hardness and yield strength, and (b) strain hardening exponent

Table 1. Mechanical properties resulting from different aging profiles

\begin{tabular}{|c|c|c|c|c|}
\hline $\begin{array}{c}\text { Aging time, } \\
t_{\mathrm{a}}(\mathrm{h})\end{array}$ & $\begin{array}{c}\text { Hardness, } \\
H(\mathrm{MPa})\end{array}$ & $\begin{array}{c}\text { Yield Stress, } \\
\sigma_{\mathrm{y}}(\mathrm{MPa})\end{array}$ & $\begin{array}{c}\text { Strain-hardening } \\
\text { exponent, } n\end{array}$ & $\begin{array}{c}\text { Diagonal Length, } \\
D(\mu \mathrm{m})\end{array}$ \\
\hline 6 & 1452 & 348 & 0.070 & 805 \\
\hline 36 & 1667 & 445 & 0.066 & 790 \\
\hline 94 & 1432 & 344 & 0.110 & 808 \\
\hline
\end{tabular}




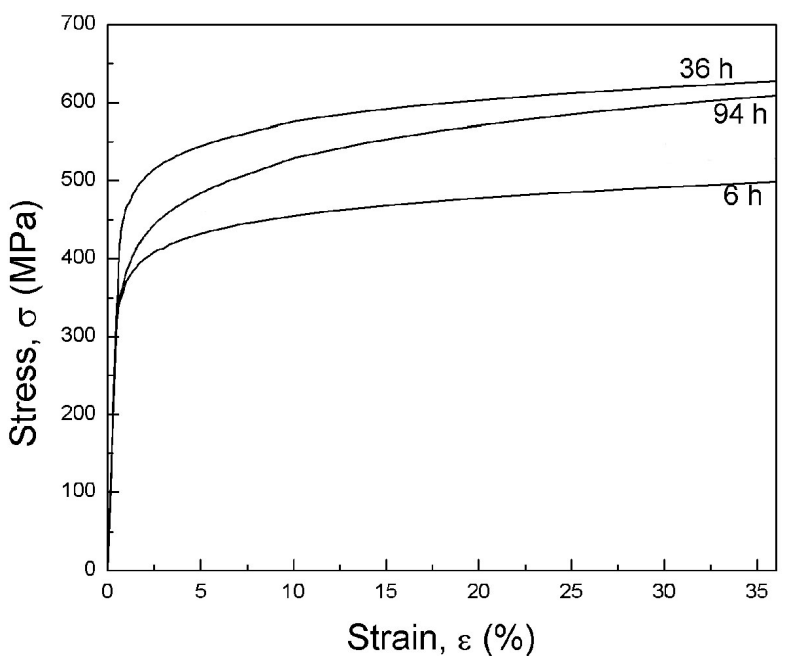

Figure 2. True stress-true strain curve for various aging profiles

For each $t_{\mathrm{a}}$ profile, a block of $3 \mathrm{~cm}$ in length and $1 \times 1 \mathrm{~cm}^{2}$ in cross-section was polished down to $1 \mu \mathrm{m}$ diamond paste prior to Vickers indentation with a load of $700 \mathrm{~N}$ to create a large indent. Then, the indented block was sectioned perpendicular to the indented surface, along its median plane using a $25 \mu \mathrm{m}$ thick copper wire in the electro discharge machining to minimize any mechanical deformation from the sectioning process. The sectioned planes were gently polished down to $0.25 \mu \mathrm{m}$ diamond paste, and the arrays of micro-hardness indentations were conducted on the deformed region with a load of $0.5 \mathrm{~N}$ (the diagonal length of the micro-indent is about $22 \mu \mathrm{m}$ ) in order to probe for hardness map underneath the large indent, as schematically depicted in Fig. 3. For generalization, the $\mathrm{x}$ and $\mathrm{z}$ distances were normalized with large indent diagonal on the xy plane.

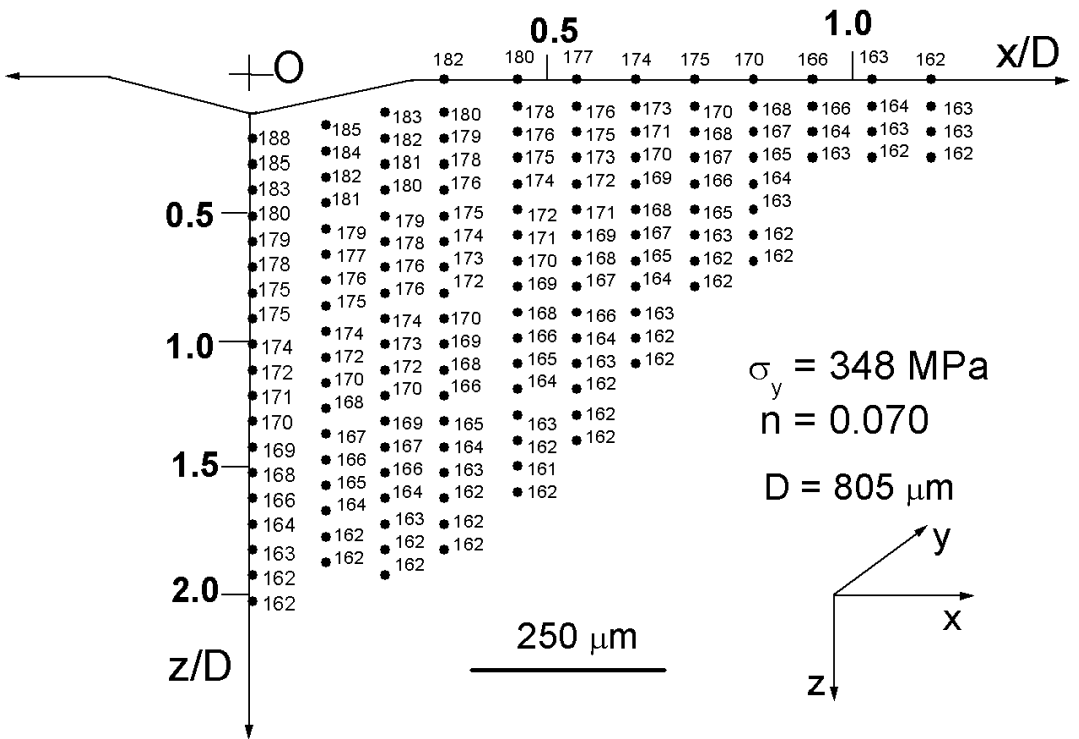

Figure 3. A typical microhardness map on the cross-section of the large indent (xy is the plane for indentation along the $\mathrm{z}$ direction)

In order to convert the microhardness map shown in Fig. 3 to a contour plot of equivalent plastic strain $\varepsilon_{\mathrm{p}}$ map, the cylindrical samples of $15 \mathrm{~mm}$ in height and $10 \mathrm{~mm}$ in diameter (polished to $0.25 \mu \mathrm{m}$ finish) from each aging profile were compressed to various levels of compressive plastic strain $\varepsilon_{\mathrm{p}}$ (with quasi-static strain rate of $10^{-3} 1 / \mathrm{s}$ ), and indented with a load of $0.5 \mathrm{~N}$. Thus, the correlation between compressive plastic strain $\varepsilon_{\mathrm{p}}$ and hardness value was established, see example in Fig. 4 for the $6 \mathrm{hr}$ aging case. 


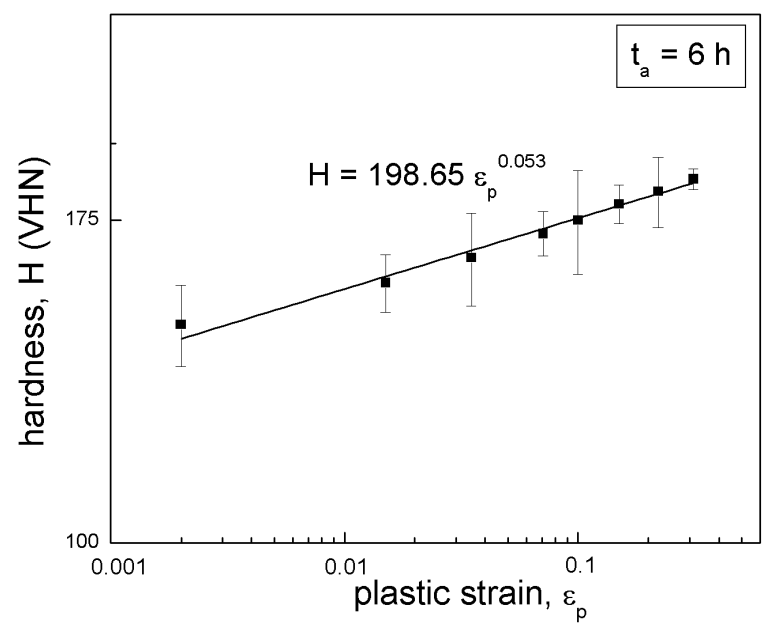

Figure 4. A correlation between hardness number and compressive plastic strain used to convert microhardness map to contour plot of plastic strain underneath the indenter

\section{RESULTS \& DISCUSSION}

The plastic strain distribution maps (normalized by indent diagonal, $D$ ) underneath the Vickers indenter are illustrated by iso-strain contours shown in Fig. 5, for both the case of similar $\sigma_{\mathrm{y}}$ but different $n$ (6 and $94 \mathrm{hr}$ aging in Fig. 5a) and the case of similar $n$ but different $\sigma_{\mathrm{y}}(6$ and $36 \mathrm{hr}$ aging in Fig. $5 \mathrm{~b})$. The $\mathrm{x} / \mathrm{z}$ distances are normalized by indentation diagonal on the xy plane with the contour line for visual guiding only. Note that the unevenly-spaced contour interval is selected for easier contour line drawing only since the typical deformation field underneath the indenter shows large strain gradient near the tip with gradually less gradient further away. Figure 5a suggests that the strain field is relatively shallower for a higher $n$ material with similar $\sigma_{\mathrm{y}}$. This is consistent with general observation of indentation sink-in effect for high $n$ material (e.g. annealed sample) because material has large resistance to plastic deformation with limited spread of plasticity ${ }^{(3-5)}$. On the other hand, Fig. 5b suggests that the strain field is relative smaller in both $\mathrm{x}$ and $\mathrm{z}$ directions for a higher $\sigma_{\mathrm{y}}$ material with similar $n$. The range of plastic strain value shown in Fig. 5 is consistent with the range of 0-0.36 in well annealed copper sample ${ }^{(1)}$.

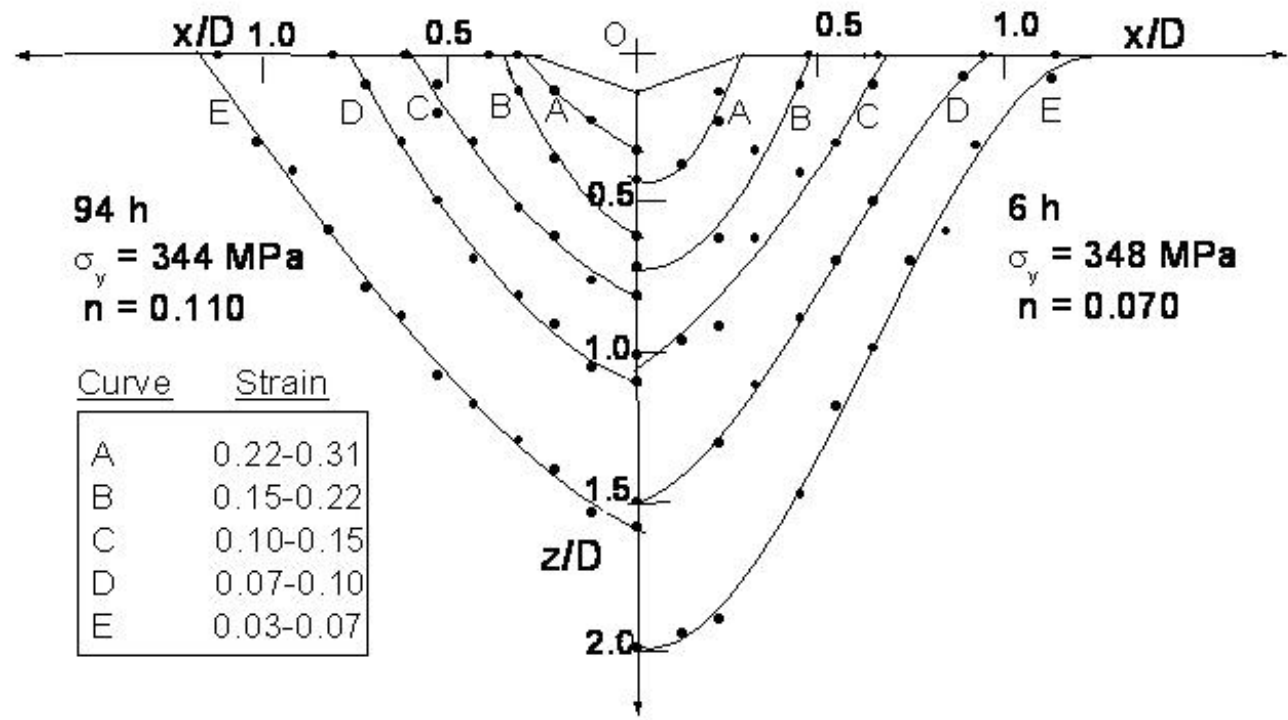

(a) 


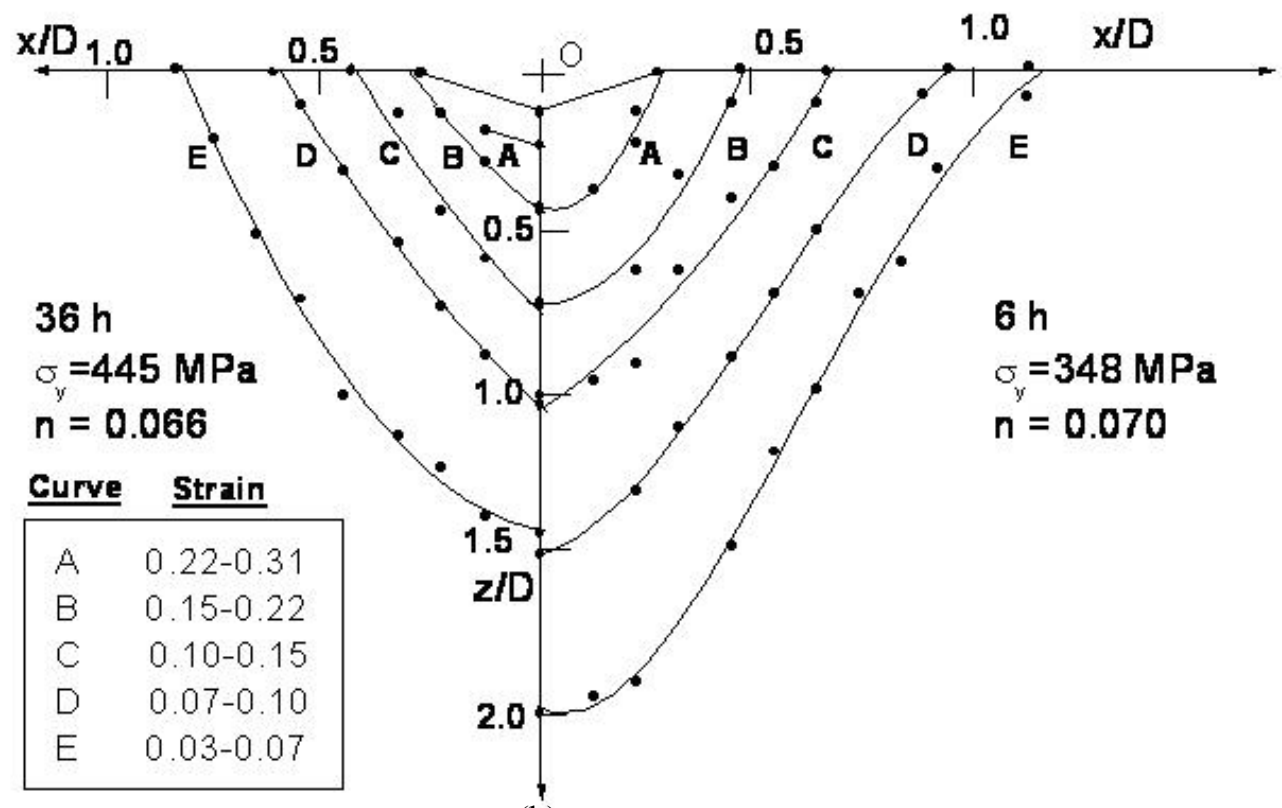

(b)

Figure 5. The contour plot of plastic strain distribution underneath Vickers indenter for (a) 6 vs. $94 \mathrm{hr}$ aged sample ( $\operatorname{similar} \sigma_{\mathrm{y}}$ but different $n$ ) and (b) $6 \mathrm{vs.} 36 \mathrm{hr}$ aged sample (similar $n$ but different $\sigma_{\mathrm{y}}$ ). The $\mathrm{x} / \mathrm{z}$ coordinates are normalized by large indenter diagonal reported in Table 1. Note that the contour line is drawn for visual help only.

\section{CONCLUSION}

Deformation behavior underneath Vickers indenter was experimentally correlated with the power-law plasticity parameter, yield strength and strain hardening exponent, via a cross-sectional micro-indentations of the macro-indentation using Vickers tip. The samples were carefully aged to have a pair of similar yield strength but different strain hardening exponent, and a pair of similar strain hardening exponent but different yield strength. Micro-hardness map was converted to plastic strain field via micro-indentation of same materials at various uniaxial compression levels. The contour plot of plastic strain for each pair was compared for to identify the individual effects of yield strength and strain hardening exponent. It was found that work hardening behavior of the material is relatively more influential in determining the plasticity spread in the z-direction (i.e., the loading direction) than in the x-direction; whereas, elastic limit (yield strength) of the material affects the plasticity spread in both loading and lateral directions.

\section{References}

(1) Chaudhri, M.M., Subsurface Strain Distribution Around Vickers Hardness Indentations in Annealed Polycrystalline Copper, Acta. Mater., Vol. 46, (1998), pp 3047-3056.

(2) Wood, J. and McCormick, P.G., Acta. Metall., Vol. 35, (1987), pp 247.

(3) Dao, M. et al, Computational Modeling of the Forward and Reverse Problems in Instrumented Sharp Indentation, Acta Mater., Vol. 49, (2001), pp 3899-3918

(4) Giannakopoulos, A.E. et al, Analysis of Vickers Indentation, International Journal of Solids and Structures, Vol. 31, No. 19, (1994), pp 2679-2708

(5) Oliver, W.C. and Pharr, G.M., An Improved Technique for Determining Hardness and ElasticModulus Using Load and Displacement Sensing Indentation Experiments, Journal of Materials Research, Vol. 7, No. 6, (1992), pp 1564-1583

(6) Doener, M.F. and Nix, W.D., A Method for Interpreting the Data from Depth-Sensing Indentation Instruments, Journal of Materials Research, Vol. 1, (1986), pp 601 